YEARBOOK of ANTITRUST and REGULATORY

STUDIES www.yars.wz.uw.edu.pl
Peer-reviewed scientific periodical, focusing on legal and economic issues of antitrust and regulation. Creative Commons Attribution-No Derivative Works 3.0 Poland License.

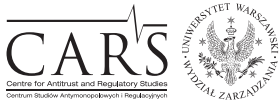

Centre for Antitrust and Regulatory Studies, University of Warsaw, Faculty of Management www.cars.wZ.uw.edu.pl

\title{
Design of Regulatory Contracts - Example of the Urban Transport Industry
}

by

\author{
Joanna Piechucka*
}

\section{CONTENTS ${ }^{* *}$}

I. Introduction

II. Economic issues in the design of regulatory contracts

1. Informational asymmetries

2. Transaction cost

3. Regulatory capture

III. The French urban public transport industry

1. Legal and organizational background

2. Economic issues in the industry

IV. Final remarks

\section{Abstract}

The present article discusses economic issues related to the design of optimal regulatory contracts on the example of the urban public transport industry. It highlights the importance of the design of efficient regulatory contracts in the context of changes facing the urban transportation industry in the European Union. Furthermore, it provides an overview of the main issues put forward in economic literature related to the design of regulatory contracts. It discusses several problems relevant in this context such as informational asymmetries, transaction costs, and regulatory capture. It also comments on a selection of views presented in economic literature dealing with these issues.

Finally, the article presents the regulatory framework, contractual practices and characteristics of the French urban public transport industry. France is well known

* PhD candidate, Paris School of Economics - Université Paris 1 Panthéon Sorbonne, Economist, Microeconomix, tel. +33 1755789 88; joanna.piechucka@psemail.eu.

** Article received: 11 March 2016; accepted: 4 May 2016. 
for its long standing tradition of contracting between the State and the private sector in transportation. The analysis of the French example may help to prove useful insights in this regard.

\section{Résumé}

Cet article s'intéresse à la question de la conception de contrats réglementaires optimaux d'un point de vue économique dans le cadre du transport public urbain. Il met en évidence le fait qu'il est important de concevoir des contrats réglementaires efficaces dans le contexte des changements qui ont lieu actuellement dans le secteur du transport urbain dans l'Union Européenne.

En outre, l'article fourni un aperçu des principales questions mises en avant dans la littérature économique liée à la conception des contrats réglementaires. Il discute des problèmes qui peuvent survenir dans ce contexte, telles que les asymétries d'information, les coûts de transaction, et la capture réglementaire. Il présente et critique également des arguments avancés dans la littérature économique qui traite ces questions.

Enfin, l'article présente le cadre réglementaire, les pratiques contractuelles et les caractéristiques de l'industrie du transport public urbain en France. La France est bien connue pour sa tradition de relations contractuelles entre l'Etat et le secteur privé dans le secteur du transport. L'exemple du transport public urbain en France peut fournir des renseignements utiles à cet égard.

Key words: contracts; informational asymmetries; regulatory capture; transaction costs; urban public transport.

JEL: L14, L51, L92

\section{Introduction}

The goal of this article is to introduce the main economic problems that arise in the design of optimal regulatory contracts, and to highlight solutions that have been proposed by economic literature in order to overcome them. The example of the urban transport industry is used to illustrate the analysis.

In the last three decades, the organization and regulation of urban public transport in Europe has undergone considerable changes with contracting becoming a tool increasingly used by public authorities. In this context, the design of efficient regulatory contracts is essential for the provision of an economically efficient, high-quality service.

Urban transportation plays an important role in Europe's economic activity. 74\% of EU's population currently lives in urban areas (EC, 2015); 
approximately 57 billion passenger trips were made via local public transport in the EU in 2012 (UITP, 2014). However, urban public transport has migrated from being a profitable industry, with a high modal share, to a loss-making one with, in most cases, a minority modal share. To address these issues, reduce operating costs as well as to improve performance and service quality, the sector experienced a move away from public ownership and operation to its privatization.

Designing efficient regulatory contracts between public authorities and transport operators may seem problematic. First, the former may not be in a perfect position to observe the productive capacity and decisions made by latter. These informational constraints may limit the efficiency of industrial control exercised by transport authorities over transport operators, and in turn make it possible for the operators to receive informational rents. Second, if the task delegated to the transport operators is complex, contracts may be costly to design, enforce, and re-negotiate. Future contingencies may be difficult to predict and unforeseen costs may appear. Finally, regulatory decisions ${ }^{1}$ may be dependent on the pressure of local interest groups, which may be willing to influence them for the benefit of their private interest. These issues are of key interest to economists.

Section II of this paper provides an overview of the main problems put forward in economic literature in the design of regulatory contracts ${ }^{2}$. These include informational asymmetries, transaction costs and regulatory capture. It also presents an overview of different solutions proposed in this regard by economic literature. Section III focuses on the example of the regulatory framework, contractual practices and characteristics of the French urban public transport industry. The French case provides useful insights regarding the design of efficient regulatory mechanisms. Overall conclusions can be found in section IV.

\section{Economic issues in the design of regulatory contracts}

The delegation of a task by a public authority to the private sector may be associated with problems related to the presence of informational asymmetries between the public authority and the firm to which a task is

\footnotetext{
1 Regulatory decisions are understood as decisions made by the relevant (possibly local) transport authority when delegating the operations of a service to a transport operator.

2 Throughout the text, the term regulatory contract will refer to a contract binding the relationship between the relevant public authority responsible for providing a given service and a private operator to whom the contract is delegated to.
} 
being delegated to. Informational asymmetries further give rise to other difficulties such as transaction costs or regulatory capture. The purpose of this section is to introduce these terms and explain their role in the design of optimal regulatory mechanisms. It also provides an overview of solutions put forward by theoretical and empirical literature on this subject. This discussion is general in its nature and refers to a task that a public authority (hereafter, principal) delegates to a private company (hereafter, agent) ${ }^{3}$.

\section{Informational asymmetries}

The agent may have more complete information about the task to be performed than the principal itself. The informational constraints the principal faces may affect the contracting process between them. Two types of informational asymmetries are discussed in economic literature: adverse selection and moral hazard ${ }^{4}$, both of which can be problematic in optimal contract design.

As defined by (Laffont and Martimort, 2002) 'agents to whom the task has been delegated to by a principal may chose actions that affect value or trade or, more generally, the agent's performance'. By delegating the task, the principal loses control of these actions. In particular, moral hazard occurs as the agent can take actions which are unobserved either by the principal who offers a contract or the court of law that enforces it. They cannot be contracted upon, as their value cannot be verified. The action may concern the effort that the agent puts forward when providing the service. Effort may positively impact the agent's production level but, at the same time, it may provide a disutility to him. Effort can be understood as the intensity of work put into performing a task, such as engaging in cost-reducing activities. On the other hand, examples of negative effort may include purchasing materials at high prices, allocating excessive perks to management, putting private career opportunities over efficiency, etc. Moral hazard significantly limits the extent of control exercised by the principal.

Adverse selection occurs when the operator has private information. The informational advantage may concern, for instance, its technological capabilities. The existence of adverse selection allows the agent to extract an informational rent when contracting with the regulator. To illustrate this, while the operator knows its cost of producing a given level of output (for a given level of cost-reducing effort), this data is not known to the regulator. In other words, the regulator does not know whether the operator bears high

\footnotetext{
3 This terminology refers to the terminology used in incentive economics.

${ }^{4}$ For a more general introduction to these terms see (Laffont \& Martimort, 2002).
} 
or low costs for performing the task. At the same time, the regulator must ensure that the firm is willing to perform the task, even if it faces high costs. A firm with low costs will thus enjoy a rent, as in the presence of asymmetric information the regulator does not know what costs the transport operator actually faces.

Of course, regulators may engage in collecting and exploiting data in order to limit the informational constraints they face. Operators may also be subject to audits, which allow the regulator to verify a given operator's actual costs. However, audit systems make it possible to only verify whether costs are correctly reported, that is, according to standard audit procedures. They do not resolve the problems of adverse selection and moral hazard.

The new theory of regulation considers informational asymmetries to be central in the contractual relationship between governments and firms. It adopts a normative approach to deal with these issues by assuming that regulatory contracts are optimally designed by regulators, who maximize social welfare through sophisticated mechanisms.

In line with this approach, (Laffont and Tirole, 1986) derive optimal regulatory mechanisms when informational asymmetries concerning production costs are the main concern in contracting. In their framework, the principal does not observe either productive capabilities of the operator or its cost-reducing efforts. The principal maximizes social welfare and must ensure that the agent is willing to perform the task.

They show that under informational asymmetries, the trade-off the principal faces is to make the agent reveal its productive capabilities as well as to provide the agent with incentives for cut costs. The two extreme cases are a fixed-price and cost-plus contracts. Under a fixed-price contract, the agent is paid a fixed sum for performing a task delegated by the principal, regardless of the production costs actually incurred. This type of contract provides incentives for cost cutting. Under a cost-plus contract, the production costs incurred by the agent are fully reimbursed. The agent then reveals the costs he actually faces.

Under moral hazard, the principal cannot fully reimburse all costs covered by the operator. In such a situation, the agent would not have any incentives to engage in any cost-cutting efforts, and would always manage to increase its expenditures. However, under adverse selection, the principal is not willing to implement a fixed-price contract. Under such a contract, the agent would have the incentive to understate its productive efficiency.

The resulting optimal regulatory mechanism under informational asymmetries is an incentive contract, where the principal partially shares costs with the agent. The contract is composed of two parts: a fixed-sum and a partial cost reimbursement. The optimal contract can be implemented by 
asking the agent to announce its costs for performing the task. The transfer will then depend on the announced costs and the actual realized costs. The higher the announced costs, the lower the fixed-sum, and thus the lower the fraction of cost overruns or underruns that will be shared with the principal.

The optimal scheme is thus to propose a menu of linear contracts. Different types of firms will then self-select the contract, depending on their type (how efficient they are). By self-selecting a contract, they reveal their "type". This is the so-called second-best solution attainable under informational asymmetries.

The model derived by (Laffont and Tirole, 1986) provides a normative approach to how optimal regulatory contracts should be designed. However, introducing a menu of linear contracts may be difficult in practice, as calculating an optimal menu may be complex. As a result, incentive contracts have not been widely used in practice.

Literature has proposed other solutions that allow theory to coincide more easily with reality. (Rogerson, 2003) shows that, at least in some $\operatorname{cases}^{5}$, a menu of only two contracts that an agent can chose from allows to capture more than $75 \%$ of the gains achievable under a complex menu of linear contracts. These two contracts are a fixed-price and a cost-plus contract. Intuitively, the above can be explained in the following manner from an economic standpoint. By offering a cost-plus contract, the principal ensures that even an agent with low efficiency will be willing to perform the task. However, this type of contract does not provide any cost-cutting incentives for the agent. The principal then decides on the price which it will set when offering a fixed-price contract, which will provide cost-cutting incentives for agents that are more efficient. The principal faces the following trade-off when deciding on the price. A lower price allows the principal to pay less when the contract is accepted by the agent. However, the probability that the agent chooses a fixed-price contract, instead of a cost-plus contract, is then also lower.

(Chu and Sappington, 2007) extend this model further to more general circumstances $^{6}$. In particular, they show that when informational asymmetries on the cost efficiency of the agent are particularly pronounced, then the menu of two contracts proposed by (Rogerson, 2003) does not perform so well. They suggest a solution where the principal offers the agent a choice between a linear cost-sharing contract and a cost-plus contract. Under the linear cost-sharing contract, the principal chooses the fixed-rate and the

5 The model considers an agent with a quadratic utility function and production costs that are a realization of a uniformly distributed random variable. A more technical discussion of the model is provided in the article itself.

6 The technical details of the model are provided in the article. 
reimbursement-rate so as to minimize its expected procurement costs. This solution makes it possible to capture at least $73 \%$ of the gains obtained when proposing a menu of linear contracts. In the setting analyzed by (Rogerson, 2003), it captures $90 \%$ of these gains.

The presence of informational asymmetries may lead to further problems such as transaction costs or regulatory capture. These are discussed in the next subsections.

\section{Transaction costs}

Transaction costs have their origins in contractual theories commenced by (Coase, 1937) and (Williamson, 1975). Transaction costs arise from the costs of seeking out buyers and sellers and arranging, policing and enforcing agreements or contracts in a world of imperfect information (Cowen and Parker, 1997).

Given that contracting takes place under asymmetric information, delegating a task to a firm (rather than public authorities providing it by themselves) may result in transaction costs. These reflect the difficulty in designing fully contingent contracts. In particular, when the task to be performed by the transport operator is complex, regulatory contracts may be costly to design, enforce, and re-negotiate.

It might be particularly difficult for the principal to clearly specify the task to be performed by the agent since the principal may lack the necessary technical expertise. Relevant information may be difficult to obtain. Designing the task may appear to be costly, especially when the delegated task is complex. In addition, there may be uncertainty as to the future economic situation at hand.

Contract enforcement requires the monitoring of the task performed by the agent. This, however, proves to be problematic for the principal. Necessary data collection may require costly studies. The principal may thus content itself with the data provided by the operator and may decide not to involve itself in extensive data collection or careful monitoring. In the absence of reliable and complete data on the service provided, the enforcement of the regulatory contract will not be carried out efficiently.

As future contingencies may be difficult to predict at the moment of designing the contract, the regulatory contract is likely to be incomplete. As stated by (Williamson, 2002), 'all complex contracts are unavoidably incomplete. For this reason, parties will be confronted with the need to adapt to unanticipated disturbances that arise by reason of gaps, errors and omissions in the original contract.' An agent may engage in opportunistic behavior ex ante in order to 
win the contract, by anticipating that it will be able to re-negotiate ex post terms not covered by the contract (Prager, 1990). The principal may thus face unforeseen costs related to the re-negotiation of the contract.

(Bajari and Tadelis, 2001) consider ex post changes related to contract re-negotiations. They suggest the main problem the principal faces when delegating a task to an agent are in fact ex post re-negotiations. In line with this view, they develop a model that incorporates moral hazard and transaction costs related to contractual design and re-negotiations. Restricting their analysis to two types of contracts (fixed-price and cost-plus), they shed light on when each type of contract should be used.

In their model, the principal wants to delegate a task to an agent that can induce cost-cutting efforts when performing the task. The principal provides the agent with a design of the task the agent is to perform - the more complete the design, the lower the probability of re-negotiating changes in the contract ex post. However, providing a more complete design is also associated with higher costs ex ante for the principal.

Inspired by the construction industry, they show that most of the contracts observed in reality are simple variants of fixed-price and cost-plus contracts. Fixed-price contracts provide incentives for cost-cutting. However, if the design of such contracts remains incomplete, their contract re-negotiation costs are high. Cost-plus contracts, on the other hand, lack cost-cutting incentives but are better for ex post adaptations. The resulting basic trade-off lies between providing ex ante incentives for cost-cutting and avoiding ex post transaction costs related to re-negotiations.

This model makes it possible to draw certain conclusions regarding when best to use each type of contract. Complex tasks (more costly to design) will be accompanied by a high probability of ex post adaptations. These will be delegated using cost-plus contracts. On the other hand, simpler tasks (less costly to design) will be accompanied by a small probability of ex post adaptations. These are best administered using fixed-price contracts which provide cost-reducing incentives.

At this point, it seems interesting to discuss the related choice of the award mechanism. (Bajari, McMillan and Tadelis, 2009) notably argue that contract choice may be interrelated with the choice of the award mechanism.

By providing an empirical analysis of the US construction sector, they study the determinants of choosing between 'competitive bidding' and 'negotiations'. In their analysis, they consider the interplay of contracts and award mechanisms as well as the transaction characteristics that determine them. In particular, they suggest that the choice of contract type may influence the choice of the award mechanism. Since the price is the most important factor for fixed-price contracts, it is easy to award them by way of competitive bidding. On the 
other hand, under a cost-plus contract, costs will not be reflected by bids in a meaningful way. In this context, they refer to management literature that shows that fixed-price contracts are awarded mainly through auctions and costplus contract via negotiations. Negotiations are therefore an award mechanism better suited to complex services, while competitive tendering is recommended for services that are simpler to describe.

They find a positive correlation between negotiations and a measure of complexity of the project. They suggest that ex ante projects may be incomplete and that ex post changes may be needed. In this context, the use of competitive bidding may come at a cost of losing valuable information at the moment of contracting and, if fixed-price contracts are used, ex post changes may be insufficient. The use of auctions (often requiring fixed-price contracts) may be inefficient when information ex ante is valuable and when ex post changes are anticipated.

The next section discusses another relevant issue in the design of regulatory contracts, that is, regulatory capture.

\section{Regulatory capture}

Regulatory capture refers to a situation where regulatory decisions are made in favor of specific interest groups. This issue is closely related to the privateinterest theory of regulation (Stigler, 1971; Peltzman, 1976; Becker, 1983).

Regulatory decisions are not necessarily made by benevolent authorities. On the contrary, they may be dependent on the pressure of local interest groups, which may be willing to influence regulatory decisions for the benefit of their private interests.

Firms may impact regulatory choices by providing regulators with incentives. These incentives will be the instrument of influence and source of regulatory capture. Incentives may include bribes or payments for political purposes (for instance, to finance a political campaign). They may also consist of a promise of future employment. Regulators may wish to find jobs in the future in the industry which they are currently responsible for (the "revolving door" phenomenon).

How is regulatory capture problematic in the design of regulatory contracts? Firms may be willing to impact the choice of regulatory contracts in their favour by providing incentives to the regulator. Public authorities may be willing to stay in power, and may therefore choose regulatory contracts favouring specific interest groups. Governments may be, for instance, interested in re-election and may thus be willing to undertake actions to maximize political support in favour of votes or campaign contributions in the next election. 
The next section presents the organizational and contractual practices in the French urban transport industry. It highlights the importance and extent of the abovementioned issues in the contracting process in this industry. France is well-known for a long tradition of contracting between the State and the private sector in transportation. The example of the French urban public transport industry may help to provide some useful insights as to the design of efficient regulatory mechanisms.

\section{French urban public transport industry}

\section{Legal and organizational background}

The legal framework of urban public transport in France, outside the Ile-deFrance region ${ }^{7}$, dates back to the Transport Law of $1982^{8}$. This Law provided a guideline for public passenger transport in the urban transport areas and established the concept of economic and social efficiency by providing the right to low-cost public transport. The institutional organization of public transport was then clarified by separating the functions of the organizer and the operator of the relevant service. It made local public authorities responsible for organizing urban public transport by defining, financing and organizing regular public passenger transport in urban transport areas. Local public authorities were left with the choice whether to organize and provide such services by themselves, or to delegate the relevant responsibilities to a completely private, or to a public-private operator. No national regulator of the sector exists. Local authorities are considered 'regulators' in their urban transport areas.

Until 1993, local authorities were not obliged to choose a transport operator by way of a competitive tendering process. The Sapin $\mathrm{Law}^{9}$ made competitive bidding compulsory for the award of a contract for the provision of a public service. The aim of the law was to prevent collusion and corruption as well as to enhance competition between industry operators. The introduction of

7 The regulation of transport in the Ile-de-France region differs from the rest of the country. In this particular region, transport is organized by STIF (franc. Syndicat des Transports d'Ilede-France) half of which is formed by State representatives, the other half being formed of the Local Authority, the Ile de-France région, departments and city of Paris representatives. The association is presided over by a State representative who has the casting vote. This article focuses on the regulation of the industry in France outside the Ile-de-France region.

${ }^{8}$ Loi n ${ }^{\circ} 82-1153$ du 30 décembre 1982 d'orientation des transports intérieurs.

9 Loi $\mathrm{n}^{\circ}$ 93-122 du 29 janvier 1993 relative à la prévention de la corruption et à la transparence de la vie économique et des procédures publique. 
this Law made it mandatory for local authorities to open a tender procedure before awarding a public contract. It did not, however, forbid the use of negotiations in the procedure. As a result, operators can be selected in a twostep procedure - a pre-selection step (with the use of competitive bidding) and a negotiation phase (allowing for subjective selection criteria). The French model of regulation, combining competitive tendering with a phase of negotiations, allows for the use of subjective selection criteria, which play an important role in regulatory relations between local authorities and transport operators in France.

The figure below presents the urban transport networks in France in 2013. It presents the difference between those regulated through delegated management and those managed directly by public authorities. $90 \%$ of urban transport networks in France are currently operated through delegated management (GART, 2015). In the case of delegated management, the operation of the service is entrusted to an operator chosen by the relevant local authority. This relationship is regulated by an agreement. In this agreement, the local authority specifies the characteristics of the service to be provided, the operator's duties to the passengers, the terms and conditions of the financing of the operator, payment and fares, as well as the choice of the regulatory contract type. The average duration of the contract is approximately 8 year (GART, 2015). The key feature of the French model is the attribution of the contract to only one operator at a time who will carry out the responsibility of providing the relevant service in the whole urban transport area.

Furthermore, most transport operators belong to a major transport group. Before 2011, nearly $70 \%$ of the operators were subsidiaries of three major groups, two of which were private while the third was semi-public (respectively Keolis, Veolia Transport and Transdev). In March 2011, the $2^{\text {nd }}$ and $3^{\text {rd }}$ of those groups merged ${ }^{10}$. As stated by the French Court of Auditors (Cour des Comptes, 2015), the urban transport sector in France presents now the characteristics of an oligopolistic market.

In practice, the two main contract types binding local authorities and transport operators in France are effectively either fixed-price and cost-plus contracts. In networks regulated under a fixed-price contract, operators receive subsidies according to their expected operating deficits. Therefore, any cost changes affect their profits. On the other hand, in networks regulated by cost-plus contracts, the organizing authority collects commercial receipts and fully reimburses the operator's operating costs, increased by a pre-defined additional amount. Under this scheme, the authority provides the operator with subsidies to cover its actual deficits. Cost changes do not, therefore,

10 Autorité de la concurrence, Décision n 10-DCC-198 du 30 décembre 2010 relative à la création d'une entreprise commune par Veolia Environnement et la CDC. 
affect the profit of the operator. In recent years, the industry has seen a move towards high-powered incentive schemes. As a result, the proportion of networks regulated under a cost-plus contract has decreased substantially from $100 \%$ in the 1970s, 60\% in the 1980s, $25 \%$ in the 1990s (Yvrande-Billon, 2006) to only $7 \%$ in 2013 (GART, 2015).

Figure 1. Urban public transport networks (outside the Ile-de-France region) in France in 2013

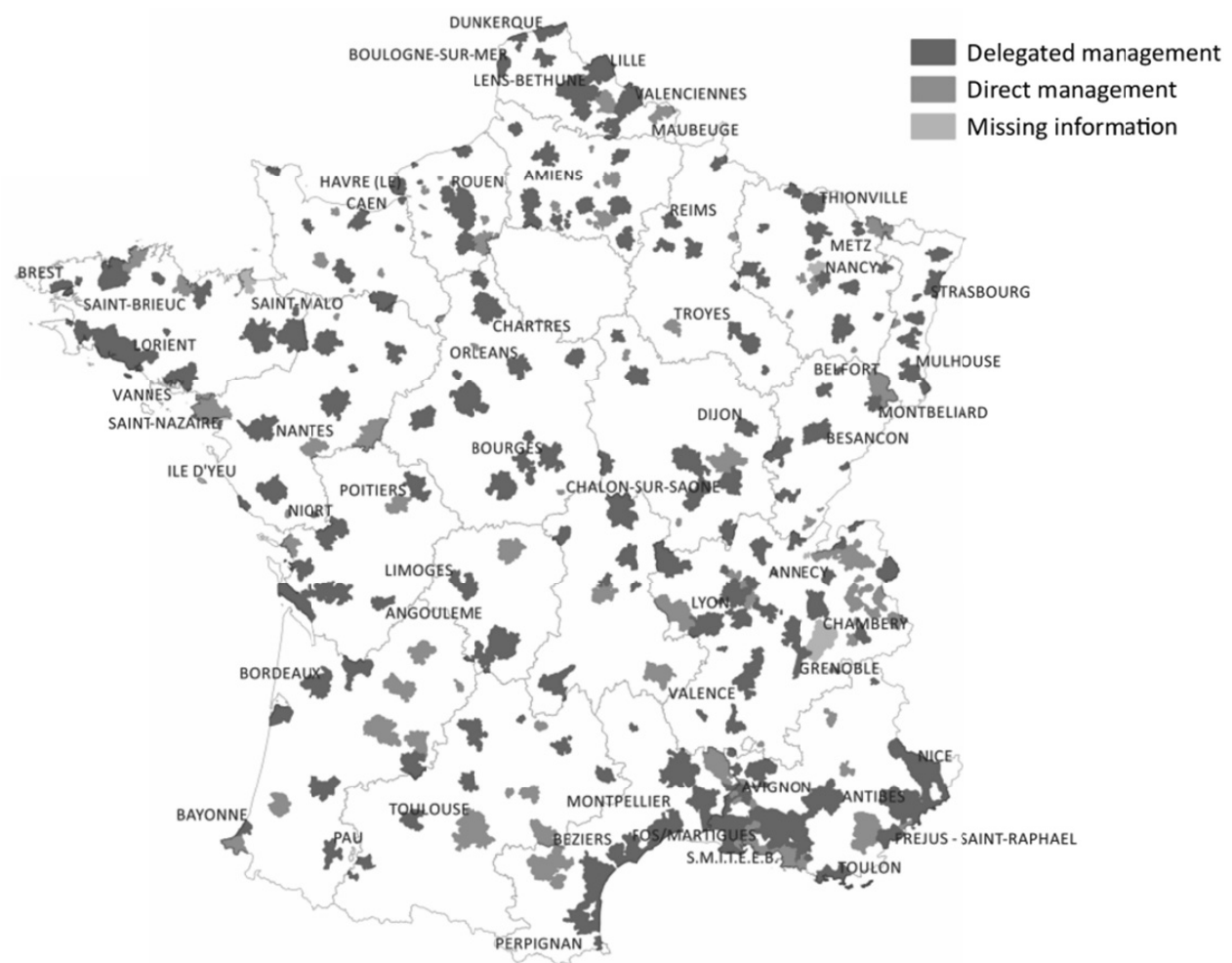

Source: Own analysis on the basis of the TCU database of CEREMA, GART and UTP.

The French urban transport industry is highly subsidized and is currently facing strong financial constraints. Commercial receipts cover approximately $29 \%$ of the operating costs of the transport operators (GART, 2015). The remaining operating costs are covered by subsidies from the State, local authorities and a special local tax paid by local firms ${ }^{11}$. Designing good

11 This transport tax consists of a local contribution of employers that makes it possible to provide additional funding for urban public transport. It is imposed on employers of both the 
regulatory contracts plays thus an important role in the financial health of the industry.

The next section discusses to what an extent problems presented in economic literature related to the design of regulatory contracts are relevant to this industry.

\section{Economic issues in the industry}

Transport operators may have private information about their technological capabilities and may undertake cost-cutting efforts (data not observable to the relevant local authority). Such informational asymmetries may affect the economic efficiency of providing the service. Indeed, informational asymmetries are a problem for the French urban transportation industry. Their presence and extent are highlighted in sector- and academic studies dealing with this industry.

Most of the operators belong to major groups that have experiences accumulated from operating both in France and internationally as well as from internal research and development activities. As a result, they have greater experience and better information than the local authorities about the costs of providing the service is question, as well as its quality. Local authorities responsible for organizing urban public transport, on the other hand, are known for being lax in assessing operating costs (see (Gagnepain \& Ivaldi, forthcoming)). Technical and financial data provided to local authorities is often not sufficiently representative of the realities of the relevant services, a problem compounded by the very limited technical expertise of their employees (Cour des Comptes, 2005). This gives rise to adverse selection.

As in most transport networks, local authorities are the ones to set the pricing policy and to finance the infrastructure. Operators can be involved in cost-cutting activities when providing the service. In particular, they may try to cut costs depending on the regulatory schemes put in place. Given the complexity and limited data on the service, it becomes difficult for local authorities to assess the cost-cutting activities undertaken by the chosen operator. Indeed, the organizing authorities in France have limited financial resources and few specialized staff members able to perform high quality audits or surveys. The insufficiency of the reports provided by operators to the organizing authority, and the complexity of the task of operating the service, make the evaluation process even more difficult. This gives rise to the moral hazard problem. transport area of a population of more than 10,000. It is collected by each urban transport area. 
Contract enforcement seems to be particularly problematic in the industry. Information provided by operators to their local authorities is often incomplete, erroneous or non-explicit (Cour des Comptes, 2015). This makes it difficult for a given authority to analyze the effectiveness and efficiency of the management of the service. Existing national regulation does not impose any conditions on transport operators on the supply of data to the relevant local authorities that would be relevant for evaluating the quality of the service they provide (Cour des Comptes, 2005). Authorities rarely engage themselves in monitoring and data collection necessary to evaluate performance and service quality. In many networks, penalties defined in the regulatory contract are not actually imposed (Cour des Comptes, 2015) ${ }^{12}$.

Moreover, as local authorities often face difficulties in precisely defining the service, contracts are likely to be incomplete. This is particularly relevant in undersized networks organized by small local authorities with limited or no specialized staff. Contracts here are thus re-negotiated throughout their duration.

Finally, the different actors taking part in providing the service (the local authority itself, the transport operators, the groups the operators are affiliated with) may prefer a certain type of contract and may thus be willing to impact the regulatory decision. This is a relevant issue to consider in the French transportation industry, a fact highlighted in academic literature on this industry discussed below.

Local authorities responsible for organizing urban public transport in France are ultimately made up of politicians representing municipal councils elected for a six-year period. These may be interested in re-election and may thus be willing to take actions to maximize their political support to gain votes or future campaign contributions. Politicians leaving the government may look for high-level jobs in the industry for which they were previously responsible for. Leaving rents in the form of higher wages or excessive profits to regulated firms puts the 'regulator' in good standing with the business and the social elites that own or control the transport firms.

Moreover, most transport operators belong to major transport groups. These groups may have important bargaining power when facing local authorities.

12 Since at least 2008, the local authority of the Rouen-Elbeuf-Austerberthe network has not managed to impose any of the penalties foreseen in the delegation contract. Moreover, in the Caen network, penalties resulting from the non-achievement of objectives related to the quality of the service to be provided are rarely imposed and the incentive mechanisms provided in the delegation contract have limited impact. To give another example, applying penalties introduced in the delegation contract of the Clermont-Ferrand agglomeration require the fulfillment of several conditions, which make their execution difficult in practice. In the Toulon network, the incentive schemes allow, paradoxically, for the operator to increase its remuneration even in the case of a negative evolution of operating results. 
In particular, they may want to aggressively maximize profits and thus might prefer fixed-price contracts. On the other hand, local authorities may also be willing to leave rents to the transport operator's employees and thus may opt for a cost-plus contract. As stated by the French Court of Auditors (Cour des Comptes, 2015), local authorities have little margin for negotiation and their relationship with operators belonging to major transport groups is often unbalanced. It is necessary to consider regulatory capture when studying the efficiency of the design of regulatory contracts.

Not surprisingly, the specifics of the French urban transportation industry drew the attention of economists. These studies provide empirical evidence of the relevance and extent of the aforementioned issues in the context of the French urban transport industry. They also provide explanations of why some of the solutions introduced to overcome these problems did not bring the expected results.

(Gagnepain and Ivaldi, forthcoming) provide empirical evidence for the importance of accounting for asymmetric information and political considerations when studying the effects and causes of regulation in the French urban transportation industry.

In their analysis, they consider the specificities of this industry segment as to the choice between a fixed-price and cost-plus contract. They assume that the regulator faces informational asymmetries and that it does not have means allowing it to make the agent reveal its real productive efficiency. Moreover, the regulator is considered to be motivated by political considerations in its choices. They adopt a positive approach to study the rationale that drives regulatory contract choices and the impact of these choices on total welfare.

Accounting for asymmetric information and political capture, they shed light on which contract type (fixed-price or cost-plus) performs better. In the framework considered, this question is not straightforward. On the one hand, fixed-price contracts provide the transport operator with cost-cutting incentives. However, subsidies paid to that operator may be excessive, as the regulator does not know the operator's productive efficiency. The regulator may thus leave an informational rent to the transport operator. The possible excessive subsidies may outweigh the positive impact on welfare of cost cuts achieved by the operator under a fixed-price contract.

Their results suggest that choosing a cost-plus contract entails higher costs for society than fixed-price contracts, the difference amounting to 3 million EUR. Yet this difference is lower when interest groups are accounted for in the welfare gap computation. In particular, higher operating costs (observed under a cost-plus regime) make it possible for the regulator to make transfers to the operator's employees. As the latter is a subgroup of the society, these transfers have a positive impact on total welfare. This in turn limits (but does 
not eliminate) the advantages to society of fixed-price contracts as opposed to cost-plus contracts. In particular, the total welfare gap between the two contract types diminishes to 1 million EUR when accounting for interest groups.

They also provide empirical evidence of regulatory contract choices being motivated by political agendas, including political objectives of local authorities, the role played by trade unions and the pressure of corporations that own (fully or partially) local transport operators. In particular, they show that a change of government from left- to right-wing entails an increase in the probability of choosing a fixed-price contract from $47 \%$ to $84 \%$. This probability increases from $48 \%$ to $60 \%$ if the operator has a public-private instead of private ownership structure.

(Yvrande-Billon, 2006) studies the industry from the perspective of transaction cost economics. She explains why the introduction of a competitive bidding procedure ${ }^{13}$ did not translate into more competition and increased efficiency. She refers to theory claiming that problems associated with competitive bidding result from contractual disabilities between the contractual parties. She highlights in particular, among other things, problems related to contract specifications, contract enforcement and ex post contract changes. In light of these issues, she provides suggestions on how the current regulatory framework of the French urban transportation industry could be improved.

She stresses the importance of providing a good service specification in the competitive bidding process. When the service to be provided is complex, an incomplete design of the contract may lead to choosing the bidder who is most aware of the shortcomings of the contract, which he may exploit in the future. She provides evidence on the relevance of this problem in the French urban transportation industry. Local authorities lack the necessary technical expertise to provide a good service specification. This is shown to be particularly true in smaller local authorities (small networks) without an employee responsible for the regulation of the sector.

Accounting for problems related to the authorities' limited accessibility to relevant data, she highlights that contract enforcement is not efficiently carried out in the industry. She suggests that, in this context, writing more complex (and also more costly) contracts with various performance clauses does not lead to adequate results. As local authorities do not have the necessary data to assess performance and service quality, operators are not incited to improve performance, even under high-powered incentive contracts. She further points out that, facing limited technical expertise, local authorities often limit

13 As mentioned before, the Sapin Law of 1993 made competitive bidding a mandatory award mechanism for choosing the transport operator to which the operation of the relevant transport network will be delegated to. 
themselves to the data supplied to them by the relevant transport operators, without collecting the necessary financial data or conducting investigations by and for themselves. In this setting, contract enforcement is not efficient because operators are not supervised well enough. Performance clauses and various sanctions provided in delegation contracts will not prove to be beneficial as long as the data collected by the local authorities is not complete and reliable.

(Yvrande-Billon, 2006) highlights also the extent of ex post contract changes in the industry. She explains that significant amendments to contracts may be the result of opportunistic behavior of transport operators. In particular, transport operators may engage in ex post opportunistic behavior by re-negotiating promises made ex ante in order to win the contract for the operation of the services in a given network. She refers to sector studies that point out that the terms of contracts are frequently re-negotiated. As operators are better informed than local authorities, and the latter lack necessary expertise to evaluate the performance of the service to be provided, re-negotiations are more likely to turn out to be for the benefit of transport operators.

These findings are followed by suggestions how the current situation in the industry can be improved. She highlights, for instance, the potential benefits of creating a national regulatory agency that would standardize performance indicators and use benchmarking to compare performance of transport operators.

In view of the economic problems encountered in the industry, some solutions have been introduced to address them. They are mean to reduce informational asymmetries between local authorities and transport operators, enhance effective competition in the industry or introduce performance indicators in the relevant contracts.

\section{Final remarks}

The goal of this article was to introduce the reader to the main economic problems that arise in the design of optimal regulatory contracts, and to highlight solutions that have been proposed by economic literature to overcome them.

The example of the French urban transport industry shows that issues discussed in economic literature seem to be indeed problematic in practice. Informational asymmetries manifest themselves in the difficulty experienced by public authorities of assessing the productive efficiency and cost-cutting efforts of transport operators. These informational asymmetries may make 
monitoring of the relevant tasks further difficult and may result in costly $e x$ post contract changes. Finally, public authorities are not necessarily interested in maximizing total welfare. They may be motivated by political considerations. These problems affect the design of regulatory contracts. Sharing the French experience may be helpful for other countries in identifying possible complications that may arise in contracting and providing adequate solutions.

The role of economists in this regard is to consider these problems and provide solutions that could be introduced in practice. Some such answers have been proposed in literature. However, there is still a need for more studies that would provide solutions that could be introduced in practice.

\section{References}

Bajari, P., Tadelis, S. (2001). Incentives versus Transaction Costs: A Theory of Procurement Contracts. The RAND Journal of Economics, 32(3), 387-407, http://dx.doi. org/10.2307/2696361.

Bajari, P., McMillan, R., and Tadelis, S. (2009). Auctions versus Negotiations in Procurement: An Empirical Analysis. Journal of Law, Economics, \& Organization, 25(2), 372-399, http://dx.doi.org/10.1093/jleo/ewn002.

Becker, G. S. (1983). A Theory of Competition Among Pressure Groups for Political Influence. The Quarterly Journal of Economics, 98(3), 371-400, http://dx.doi. org/10.2307/1886017.

Chu, L.Y., Sappington, D.E. (2007). Simple Cost-Sharing Contracts. The American Economic Review, 97(1), 419-428, http://dx.doi.org/10.1257/aer.97.1.419.

Coase, R.H. (1937). The Nature of the Firm. Economica, 4(16), 386-405, http://dx.doi. org/10.1111/j.1468-0335.1937.tb00002.x.

Cour des Comptes. (2005). Les transports public urbains. Paris.

Cour des Comptes. (2015). Rapport public annuel 2015. Paris.

Cowen, T., Parker, D. (1997). Markets in the Firm: A Market-Process Approach to Management, Hobart Paper No. 134. Institute of Economics Affairs.

Dider van de Velde, A.B.-C.-H. (2008). Contracting in Urban Public Transport. Study submitted to EC-DG TREN by inno-V, KCW, RebelGroup, NEA, Tøi, SDG, TIS., Amsterdam.

EC. (2015). EU transport in figures - statistical pocketbook 2015.

Gagnepain, P., Ivaldi, M. (forthcoming). Economic efficiency and political capture in public service contracts. Journal of Industrial Economics .

GART. (2013). L'année 2012 des transports urbains. Paris.

Laffont, J.-J., Martimort, D. (2002). The theory of Incentives: The Principal-Agent Model. Princeton University Press.

Laffont, J.-J., Tirole, J. (1993). A Theory of Incentives in Procurement and Regulation. MIT Press.

Laffont, J.-J., Tirole, J. (1986). Using Cost Observation to Regulate Firms. Journal of Political Economy, 94(3), 614-641, http://dx.doi.org/10.1086/261392. 
Peltzman, S. (1976). Toward a more general theory of regulation. Journal of Law and Economics, 19(2), 211-240, http://dx.doi.org/10.1086/466865.

Prager, R.A. (1990). Firms Behavior in Franchise Monopoly Markets. The RAND Journal of Economics, 21(2), 211-225, http://dx.doi.org/10.2307/2555419.

Rogerson, W.P. (2003). Simple Menus of Contracts in Cost-Based Procurement and Regulation. The American Economic Review, 93(3), 919-926, http://dx.doi. org/10.1257/000282803322157160.

Stigler, G.J. (1971). The Theory of Economic Regulation. The Bell Journal of Economics and Management Science, 2(1), 3-21, http://dx.doi.org/10.2307/3003160.

Tirole, J. (1986). Hierarchies and Bureaucracies: On the Role of Collusion in Organizations. Journal of Law, Economics, \& Organization, 2(2), 181-214.

UITP. (2014). Statistical Brief - local public transport trends in the European Union.

Williamson, O.E. (1975). Markets and Hierarchies: Analysis and Antitrust Implications. The Free Press.

Williamson, O.E. (2002). The Theory of the Firm as Governance Structure: From Choice to Contract. Journal of Economic Perspectives, 16(3), 171-195, http://dx.doi. org/10.1257/089533002760278776.

Yvrande-Billon, A. (2006). The Attribution Process of Delegation Contracts in the French Urban Public Transport Sector: Why Competitive Tendering is a Myth. Annals of Public and Cooperative Economics, 77(4), 453-478, http://dx.doi.org/10.1111/j.1467-8292.2006.00315.x. 